\title{
Cómo estudiar Derecho constitucional ${ }^{1}$ (Una década más tarde)
}

Domingo Garcfa BeLAUNDE

El tema que se propone este artículo puede parecer ocioso. En efecto, a quien pregunte cómo se debe estudiar una rama jurídica determinada, podríamos contestarle, simplemente: estudiando y nada más. En este sentido, si queremos saber algo de contabilidad, lo más simple sería tomar un libro de introducción a la contabilidad y empezar a leerlo. Adicionalmente, trataríamos de seguir algún curso sobre el tema, conversar con entendidos y hacer alguna práctica profesional. Lo mismo podría aplicarse a otras ramas del saber, y salvando los casos de difícil intelección, que nunca faltan, en principio cualquier disciplina puede estudiarse más o menos fácilmente, aun cuando siempre sea necesario un mínimo de lecturas, de información y de trabajo sosegado.

Sin embargo, surge la pregunta de por qué es necesario decir esto sobre el Derecho constitucional. La respuesta es simple: porque en nuestro medio, y en general en vastos sectores de la América latina, el Derecho constitucional se da por sabido, generalmente por ósmosis o por ciencia infusa, lo que permite que cualquiera emita juicios u opiniones sobre la materia. Sucede así porque el Derecho constitucional parece a primera vista muy sencillo, ya que es lo que todos podemos apreciar (cuando no hay gobiernos de facto), pues sin cortapisas vemos cómo funcionan los poderes del Estado, la maquinaria judicial, el aparato le-

El presente texto fue publicado originalmente en esta revista hace ya más de diez años (Derecho n. $.^{\circ} 39,1985$ ), y desde entonces ha sido sucesivamente reimpreso, la última vez en forma de folleto (Ediciones Peruanas, Lima, 1994). A pedido de diversos colegas y amigos he optado por publicarlo nuevamente, debidamente revisado y corregido, dentro del marco de la fecha en el que fue preparado. Pero adicionalmente, y en vía de complemento, agrego un apéndice de similares dimensiones, titulado "Una década más tarde", que por sí solo se explica (D.G.B.). 
gislativo, los partidos políticos, el Ministerio Público, etc.; se adquiere así la sensación de lo fácil. Ésta no sólo es una característica del hombre común y corriente, sino también del político, ya que la Constitución es, recordémoslo, un texto que regula jurídicamente fuerzas y relaciones políticas, que permite que el político se sienta autorizado, diremos mejor, «investido de autoridad", para hablar, si es posible ex cathedra, sobre problemas constitucionales. La curul parece otorgar una sabiduría que podríamos llamar "adhesiva»: sentarse en el escaño es adquirir conocimientos. Es cierto que existen excepciones, y nunca faltan parlamentarios que tratan de ir más allá y obtener un mejor conocimiento sobre el tema: pero no es lo más frecuente. Esta tarea por lo general es dejada a las asesorías del Parlamento y de sus comisiones, con el agravante de que si se carece de tales asesores el problema queda sin resolver. Tema aparte es la utilización política de la Constitución, es decir, su instrumentalización, de la que no tratamos ahora, pues nos alejaría de nuestro propósito.

Adicionalmente, el hombre de Derecho en general (jueces, abogados, notarios, estudiantes, etc.), incursiona con facilidad en el tema constitucional. Es interesante advertir que en nuestro medio -no tanto a nivel profesional, sino a nivel académico- existe un cierto respeto por las áreas. Así, si bien en principio cualquier abogado podría atender simultáneamente problemas de orden civil, mercantil o industrial, al momento de abordar tales temas en dimensiones mayores (políticas, académicas, etc.) tiene un cuidado especial, pues advierte que existen especialistas en diversas áreas cuyas opiniones es conveniente tener presente. Pero si ello no fuera posible, queda siempre el recurso de que el abogado acometa la tarea de estudiar él mismo el problema y buscar una solución a su inquietud. Pero, como repetimos, lo que se observa en las diversas ramas del Derecho no sucede en el Derecho constitucional, en donde no se toman estas precauciones, sino que de frente nos lanzamos a emitir opinión. Si de aquí pasamos al mundo periodístico, es decir, a los periodistas especializados en la crónica política o parlamentaria, la cosa se agrava, pues el desconocimiento es aún mayor.

II

Ahora bien, ¿̨a qué se debe este fenómeno? ¿Qué es lo que motiva, en la gran mayoría de los casos, al hombre de Derecho y al hombre común y corriente a hablar con desenfado sobre temas y problemas constitucionales, sin base ni fundamento alguno? Intentemos alguna explicación: 
a) Presencia de gobiernos de facto. El gobierno más largo de nuestra historia -en sentido amplio- ha sido el gobierno militar (con sus dos fases incluidas) y que duró doce años (1968-1980). Adicionalmente, si hacemos un recorrido histórico de nuestras instituciones llegamos a la conclusión de que, salvo algunos contados períodos (sobre todo la llamada "República Aristocrática", que dura de 1895 a 1919), no hay tradición de estabilidad institucional. Sin entrar por ahora al detalle de si tales gobiernos fueron eficaces o no, lo cierto es que nuestra historia republicana representa formalmente una discontinuidad y un desconocimiento de la legalidad vigente. En consecuencia, si esta legalidad está representada en su ápice por la vigencia de la Constitución, ésta, desde un punto de vista histórico, no tiene mayor trascendencia. $Y$ de aquí derivan varios hechos: desconocimiento de la realidad constitucional, actitud desvalorativa frente al texto constitucional, falta de hábitos y de manejo político-constitucionales, etc.

b) Sistema educativo. Entre los múltiples problemas que afronta la educación en el país, la insuficiencia del elemento humano y lo exiguo de los recursos materiales (aulas, gabinetes, libros de texto, etc.) son los más apremiantes.

Desde esta perspectiva, podemos decir que la mala educación y los textos deficientes del curso de Educación Cívica que se imparte en los colegios, contribuyen a que el alumnado no tenga ni siquiera una noción de cuál es la estructura jurídica del poder en el Perú. Caso patente de lo que se afirma son los manuales de Educación Cívica que para los dos últimos años escolares preparó, divulgó y promovió el destacado filósofo Augusto Salazar Bondy, que, no obstante su sobria presentación, eran sumamente deficientes en la exposición y comentarios (no sólo no trataban problemas jurídicos, sino que, cuando lo hacían, tomaban referencia de leyes en veces derogadas). Similar problema se advierte en la universidad, pues un curso sobre la Constitución debería enseñarse en todas las facultades, y no sólo en las de Derecho.

c) Ausencia de libros especializados. Durante épocas de crisis (pensamos sobre todo en el docenio militar) se dictaron severas restricciones en las cuotas de dólares para importaciones, y fueron reducidas tajantemente las partidas destinadas a libros. De esta suerte, la escasa cuota de los libreros fue destinada a libros de rápida venta, sobre todo best sellers. En materia constitucional no se pasó de uno que otro manual, de manera tal que cuando se convocó a la Asamblea Constituyente en 1977, los futuros miembros de dicha asamblea no pudieron encontrar nada en librerías. Esta misma limitación tuvieron durante años los alumnos de Derecho, y sólo a partir de 1980 se ha ido salvando paulatinamente este vacío, aun cuando no de la manera como sería de esperar (sobre todo 
por el alto costo de los libros extranjeros). Por otra parte, en materia de doctrina general sólo existen dos libros nacionales: uno de Raúl Ferrero Rebagliati (1975) y otro de Darío Herrera Paulsen (1970), que, no obstante sus méritos, no han sido suficientes para cubrir esta carencia.

d) Contorno de la crisis. Aun cuando no vinculada estrechamente con la materia, es importante destacar el aspecto muy grave de la crisis por la que atraviesa el país, y de la que parece no nos libraremos en muchos años. Esto se refleja en una actitud realista en los estudiantes, quienes tratan de buscar asidero y apoyo en temas y cursos de orden "práctico", como pueden ser laboral, civil o tributario. Es decir, hay un primado de la práctica sobre la teoría; lo constitucional no reporta dividendos, y en épocas de crisis no hay tiempo para lujos ("primum vivere, deinde philosophare»).

\section{III}

Las dificultades anteriores no son insalvables, pero son aspectos muy concretos y sirven para explicar muchas cosas. Indudablemente, en el futuro próximo tales limitaciones no van a desaparecer, por lo que bien podríamos estar haciendo una simple digresión sobre un consejo inútil. Pero ello no nos priva de pensar en su paulatina superación, exponiendo algunas cuantas ideas que nos han surgido del contacto con la experiencia universitaria, tanto nacional como extranjera.

Por de pronto señalaremos algo que es elemental, pero que no resulta serlo para nuestro medio: no hay que confundir la Constitución con el Derecho constitucional, como tampoco se pueden identificar el Derecho civil con el Código Civil. Esto, que es evidente, no siempre se respeta. Se lee la Constitución y se cree saber Derecho constitucional, lo cual es no sólo una idea errónea sino incluso dañina, pues de aquí brotan un sinnúmero de errores.

Hay que tener presente que el Derecho constitucional, como cualquier otra disciplina jurídica, tiene su propio origen y su trayectoria, y maneja diversos conceptos fundamentales o categorías que tienen un significado preciso, que no pueden ser modificados arbitrariamente. Así, por ejemplo, la interpelación que hace la Cámara a un ministro es un concepto que refleja una institución con matices muy concretos, que obedece a una historia y a una estructura muy definida. Podrá discutirse las formas de presentación, el tipo de preguntas en el hemiciclo y otros detalles más, válidos sólo desde la perspectiva previa del concepto o categoría en cuestión. Igual podría decirse de la casación que realiza el Tribunal de Garantías Constitucionales en materia de hábeas corpus y 
amparo... ¿Cómo puede entenderse sus alcances ignorando el origen francés de la casación y su posterior desarrollo europeo? Y los ejemplos podrían multiplicarse, lo que demuestra que el núcleo o cuerpo central de una Constitución (y del Derecho constitucional) hay que entenderlo desde estos esquemas o categorías. Sólo a partir de ellos es posible comprender el fenómeno constitucional y afrontar los delicados problemas de su interpretación y aplicación.

Ahora bien, el conocimiento de estos conceptos fundamentales se obtiene a través de una bibliografía que presente un panorama de la disciplina ${ }^{2}$. En este sentido, lo más aconsejable es recurrir a un texto o manual introductorio, lo que no es fácil, no sólo porque existen gran cantidad de textos de iniciación, sino porque muchos de ellos son parcelarios o tendenciales, cuando no excesivamente localistas (como casi todos los franceses).

En lo personal, me permito recomendar dos manuales que considero excelentes: el de Paolo Biscaretti di Ruffia (Derecho Constitucional) y el de André Hauriou (Derecho Constitucionale Instituciones Políticas). El de Biscaretti tiene la ventaja de ofrecer un gran panorama sobre la democracia constitucional europea, con algunas referencias a otros países, con gran manejo de fuentes y un cabal sentido de las instituciones. En cuanto al texto de Hauriou, es de gran valor, pues combina, en mi opinión equilibradamente, la problemática no sólo jurídica, sino también política, y tiene además un amplio tratamiento de los países en desarrollo. $\mathrm{Si}$ bien no existe manual perfecto y ambos son susceptibles de críticas, considero que aquel que lea cualquiera de ellos, de principio a fin y sin saltarse páginas, tendrá una excelente perspectiva y podrá hablar con propiedad de esta materia.

Naturalmente que estos manuales no son los únicos ni los mejores, pero los mencionamos porque cubren un panorama amplio, son extensos sin llegar a ser excesivos, son fáciles de encontrar en nuestro medio, y adicionalmente están bien redactados y presentados ${ }^{3}$.

2 Indudablemente que el conocimiento del Derecho constitucional supone un previo contacto con el mundo del Derecho, y éste a su vez presupone un mínimo de cultura humanista (sobre todo, sociología, historia, política, filosofía), que lamentablemente en muchos centros de estudios no se desarrolla con amplitud en los primeros años de humanidades, e incluso en otros (caso de la Universidad Nacional Mayor de San Marcos) ha desaparecido.

3 Teniendo el presente trabajo un fin fundamentalmente didáctico, nos hemos limitado a señalar obras escritas directamente en nuestro idioma, así como aquellas que se encuentran traducidas (con una sola excepción, que se justifica dentro del contexto). Aclaremos que por ventura el castellano es idioma privilegiado en materia jurídica, ya que para sólo remitirnos al área constitucional, tenemos traducido el $90 \%$ de la obra básica publicada en otros idiomas. 
Muy difundido entre nosotros, y en general en el mundo hispanohablante, es el famoso manual de Duverger (Instituciones Politicas y Derecho Constitucional), que ha tenido innumerables ediciones tanto en francés como en castellano (en francés, diecisiete ediciones y en dos tomos; en castellano, un solo volumen y seis ediciones). Siendo excelente el manual de Duverger, no lo encontramos adecuado como texto de introducción, ya que es una aproximación politológica al fenómeno constitucional. Muy útil para los politólogos o científicos sociales, e incluso para el jurista que previamente ha hecho una introducción jurídica al tema, puede dar una falsa impresión al que recién se inicia.

Para aquel que desea buscar otros manuales, sea como introducción o como complemento, le señalamos algunos criterios que le pueden orientar en su elección. Ellos son:

I) debe ser un solo volumen;

II) debe tener una perspectiva jurídica, y no social o política (que en todo caso es un complemento, pero no un punto de partida);

III) debe ser posterior a la segunda guerra mundial, y de preferencia con una antigüedad no mayor de quince años;

IV) debe mostrar un panorama general, estudiando sobre todo los conceptos claves y los principales tipos de gobierno (URSS, Estados Unidos, Inglaterra, Francia, Suiza).

Si tenemos presente estos criterios, al lector le será fácil escoger un texto jurídico que le suministre los rudimentos necesarios para adentrarse en el mundo jurídico constitucional.

\section{IV}

El estudio de la Constitución no puede estar alejado del avatar político, ya que todo texto fundamental regula o pretende encauzar los fenómenos políticos, motivo por el cual debe acompañarse la perspectiva jurídica con el necesario complemento político.

Ahora bien, en materia política la variedad, los diversos puntos de vista, las líneas tendenciales, la ideologización del análisis, es aun mayor que en el Derecho, ya que en éste tenemos al menos la norma como elemento referencial. De ahí la dificultad y el riesgo de señalar una bibliografía mínima, que debe ser establecida con cautela. Teniendo presente estas limitaciones, nos permitimos señalar la siguiente bibliografía: 
a) Para una aproximación teórica.- Eduardo Andrade Sánchez, Introducción a la Ciencia Politica; Marcel Prélot, La ciencia politica; Robert A. Dahl, Análisis político moderno, y W. Abendroth y K. Lenk, Introducción a la ciencia política.

b) Para los problemas políticos cotidianos.- Maurice Duverger, Introducción a la politica, y T. Bottomore, Sociología política.

La lista anterior está relacionada con el aspecto general, que, como ineludible correlato, debe aparejar igual criterio para la realidad constitucional peruana. Es decir: es necesario que nuestro constitucionalismo lo confrontemos con nuestra historia política reciente, para lo cual pueden ser útiles Julio Cotler (Clases, Estado y Nación en el Perú) y Enrique Chirinos Soto (Historia de la República). Si bien ambos cubren un panorama muy amplio, debe tenerse presente que la realidad político-social que nos interesa es aquella que surge a partir de la caída de Leguía, es decir, en pleno inicio de la década del treinta.

Por último, un análisis del desarrollo histórico del sistema constitucional, enmarcado dentro de coordenadas políticas, sociales y económicas, puede verse en el libro de Maurice Duverger, Las dos caras de Occidente.

\section{V}

Volviendo al plano constitucional, y ya en la ruta de conocer nuestro constitucionalismo, debemos pensar en un buen texto legal y en un buen comentario.

Lo primero es tener un texto fidedigno de la Constitución Política del Perú. Ediciones hay muchas (sobre todo de carácter popular), pero no todas son acertadas ni cuidadas. Una edición útil es la preparada por el Ministerio de Justicia, que es la oficial. Entre las realizadas por los particulares, es altamente recomendable por su fidelidad, índice y documentos insertados, el Indice analítico de la Constitución Politica del Perú, debido a Jorge Power Manchego-Muñoz.

En cuanto a los comentarios sobre la nueva Constitución, hay muchos y algunos de gran valía. Retengamos por nuestra parte tan sólo los de José Pareja Paz Soldán (Derecho Constitucional Peruano y la Constitución de 1979, edición de 1984, completamente revisada), y la conjunta, debida a Enrique Bernales y Marcial Rubio (Constitución y sociedad politica). Si bien ambas obras presentan perspectivas y métodos distintos, ofrecen en conjunto un excelente panorama que enriquece la visión de nuestro constitucionalismo. 


\section{VI}

Para quien, superando el nivel del texto o manual de iniciación, quiera tener una visión más profunda de los mismos problemas, nos permitimos recomendarle algunos de los siguientes libros: Germán J. Bidart Campos, Derecho Constitucional, dos tomos; Segundo V. Linares Quintana, Derecho Constitucional e Instituciones Políticas, tres tomos; Carlos S. Fayt, Derecho Politico, dos tomos; Pablo Lucas Verdú, Curso de Derecho Político, cuatro tomos; César Enrique Romero, Derecho Constitucional, dos tomos; Mario Justo López, Introducción a los estudios politicos, dos tomos; Hermann Finer, Teoría y práctica del gobierno moderno, y Juan Ferrando Badia, Estudios de Ciencia Política.

Desde un punto de vista comparado: Manuel García Pelayo, Derecho Constitucional Comparado; Paolo Biscaretti di Ruffia, Introducción al Derecho Constitucional Comparado, y Giuseppe de Vergottini, Derecho Constitucional Comparado. Un complemento político puede encontrarse en Juan Ferrando Badía (coordinador), Regímenes politicos actuales.

\section{VII}

Dejamos constancia que aquí estamos tocando únicamente los aspectos generales y no los temas específicos del Derecho constitucional, que exigen un tratamiento aparte. Temas concretos como el de los derechos humanos, regionalismo y centralismo, unicameralismo y bicameralismo, jurisdicción constitucional, entre otros, no son tocados aquí y tienen su propia bibliografía, aun cuando aparezcan en la exposición de todo manual o texto universitario.

Por otro lado, cuando del plano general pasamos a un nivel de sofisticación, el problema se complica, pues es preciso recurrir a monografías y libros especializados, generalmente de difícil acceso.

Destaquemos que, en ese estado superior de la investigación, cuando se abordan temas muy concretos en donde es necesario recurrir a la doctrina general y al Derecho comparado, es imprescindible consultar revistas y poder leer en otros idiomas. En materia constitucional son idiomas útiles el inglés, y sobre todo el francés y el italiano (a este último idioma se traducen gran cantidad de textos alemanes, que de otra suerte serían inasequibles). 


\section{VIII}

Un paso posterior que debe realizar sólo aquel que desea dedicarse a la docencia o a la investigación seria y prolongada, es meditar y estudiar los grandes libros escritos en materia constitucional. Como se sabe, cada disciplina tiene sus clásicos, que, siendo en rigor viejos por lo que contienen, son nuevos por los problemas que suscitan y sobre todo por la forma como abordan los problemas. Nos enseñan además a trabajar con humildad, en forma seria y pausada, y generalmente nos dan información de primera mano que no se encuentra en otras partes, o que otros han repetido en forma incompleta o errónea. El Derecho constitucional tiene también sus clásicos y su lectura atenta y meditada es siempre fructífera, aun cuando a veces sea fatigoso hacerlo. Ellos son:

1) Georg Jellinek, Teoría general del Estado. Publicada en 1900 y traducida casi de inmediato al castellano en España, ha tenido sucesivas reediciones en la Argentina, a cargo de la editorial Albatros. Puede decirse en rigor que el Derecho constitucional como disciplina autónoma -si se quiere, como ciencia- se configura recién con Jellinek. Antes había constitucionalismo y constitucionalistas (en la misma Alemania es ejemplar el caso de von Gerber), pero es Jellinek el que da el armazón teórico adecuado a la disciplina, sienta las bases de su estudio y presenta un vasto cuadro histórico-jurídico que, recogiendo todo lo válido del siglo XIX, lo proyecta sobre el nuevo siglo. A fe cumplida, Loewenstein ha dicho de esta obra que no ha tenido digna sucesora ni dentro ni fuera de Alemania. Un segundo tomo, dedicado a la "Teoría particular» del Estado, no llegó a ser publicado por su autor; sólo han quedado algunos fragmentos, valiosos, pero sin el nivel de la opera magna.

2) Hans Kelsen, Teoria general del Estado. Publicada originalmente en Alemania en 1925, fue traducida por Luis Legaz Lacambra en 1933 en España, y desde entonces reeditada numerosas veces en México. A fin de divulgar esta obra, el mismo Kelsen escribió un resumen que, con el título de Compendio..., circuló ampliamente, precedido por un estudio preliminar de Luis Recaséns Siches. La obra significó, en su momento, si bien siguiendo la huella trazada por Jellinek, la primera exposición orgánica y de conjunto de la Teoría Pura, aun cuando aplicada al Estado. Años después, el autor hizo un balance y recuento de su pensamiento en su obra Teoría General del Derecho y del Estado, publicada en inglés en 1945 y traducida al poco tiempo por Eduardo García Máynez. 
3) Harold J. Laski, El Estado Moderno. Publicada por vez primera en 1925 con el título $A$ grammar of politics, es la obra más representativa de este autor, teórico del laborismo inglés, que ejerció una gran influencia en la década del treinta y que se considera un clásico en su género. El mismo Laski resumió su obra años más tarde en un opúsculo intitulado Introducción a la politica.

4) León Duguit, Traité de droit constitutionnel. Obra maestra en cinco volúmenes, cuya última edición se hizo entre 1921 y 1925, sigue teniendo actualidad. De Duguit puede verse su Manual de Derecho Constitucional, que contiene sus aportaciones básicas, traducido y publicado en Madrid en 1921 y en 1926. Junto con Maurice Hauriou, son los más destacados representantes de la llamada Escuela Sociológica del Derecho Constitucional.

5) Maurice Hauriou, Principios de Derecho Público y Constitucional. Padre de André Hauriou, autor del manual ya citado, es constitucionalista y administrativista de renombre, creador de la Teoría de la Institución, que fue luego ampliamente desarrollada por el gran jurista italiano Santi Romano. Su obra en castellano es una adaptación de dos trabajos suyos (de 1923 y 1925) de gran interés.

6) Carl Schmitt, Teoria de la Constitución. Libro clásico publicado originalmente en 1928, fue traducido en 1934 por Francisco Ayala y reimpreso innumerables veces. Si bien Schmitt ha sido muy cuestionado por su posterior adhesión al nazismo, lo cierto es que estamos ante un autor muy riguroso y de gran originalidad en todos sus escritos. Al igual que Hermann Heller, ha estado vinculado con España, lee y habla el castellano, y su única hija casó con un jurista español, Alfonso Otero ${ }^{4}$.

7) Hermann Heller, Teoria del Estado. Publicado póstumamente en alemán en 1934, este autor murió en España huyendo de la persecución nazi. Aun cuando notable por la concisión con que trabaja los conceptos, es sólo una primera parte, muy teórica y elaborada, de un trabajo inconcluso. Representa la presencia del marxismo y del enfoque sociológico en el ámbito de la comprensión del Estado.

8) Karl Loewenstein, Teoria de la Constitución. Publicada originalmente en inglés en 1957, se tradujo al castellano poco tiempo después.

4 Cf. Homenaje al profesor Alfonso Otero, Universidad de Santiago de Compostela, 1981 (incluye carta de adhesión de C. Schmitt, pp. 13-16). 
Loewenstein, un emigrado alemán discípulo de Weber que acabó sus días en los Estados Unidos, representa la unión feliz de la tradición europea con el método sajón. De gran originalidad, ha creado conceptos y esquemas de vasto alcance explicativo. Aun cuando su lectura es algo densa, se ve recompensada por el interés que despiertan sus ideas generales.

9) Carl J. Friedrich, Gobierno constitucional y democracia. La primera edición de esta obra se hizo en los Estados Unidos y en 1937. La cuarta y última edición, totalmente revisada, es de 1968 (un solo volumen), de la que procede la última versión castellana en dos tomos. Su autor logra una visión armoniosa entre el Derecho constitucional y la política, que enriquece con datos históricos y filosóficos, amén de los correspondientes a otras ramas jurídicas. Es además publicista destacado en ciencia política y filosofía del Derecho.

\section{IX}

$Y$ con esto pongo término a nuestro recorrido. No he querido -que quede claro- hacer observaciones, sugerencias o comentarios dogmáticos, sino simplemente volcar una experiencia de muchos años en el trato con la disciplina y con el modo de enseñarla. Presento además una guía de carácter abierto, que puede orientar al interesado en el torbellino de publicaciones existentes.

He pensado muchas veces que quizá lo que aquí he escrito era innecesario y seguramente era mejor no hacer nada y dejar las cosas como estaban. Pero como es mi deseo evitar que otros pierdan el tiempo en lecturas insustanciales como yo mismo lo hice en mis inicios, y como adicionalmente nadie en nuestro país -ni tampoco fuera de él- ha escrito lo que pretendo ${ }^{5}$, es que he decidido poner en circulación estas cuartillas.

Lima, enero de 1985.

$5 \quad$ Notable para su época es la obra de Adolfo G. Posada (Guía para el estudio y aplicación del derecho constitucional de Europa y América, Librería de Victoriano Suárez, Madrid, 1894), que comprende textos constitucionales, comentarios y valiosas referencias bibliográficas. Sin embargo, el maestro español no roza los temas que son el objetivo de este artículo, sin contar por cierto su inactualidad, como consecuencia natural del paso de los años. 


\section{Apéndice: Una década más tarde}

\section{I}

Hace más de diez años escribí y publiqué este ensayo sobre cómo estudiar Derecho constitucional. Fue hecho en parte para ordenarme yo mismo en algunas ideas, y para que sirviera de orientación a aquellos que pensaban introducirse en el Derecho constitucional. Fue pensado fundamentalmente para alumnos, pero también para egresados, profesionales e interesados en la problemática. Lo hice también preocupado por la forma como muchos, en forma bastante desembozada, hablaban sin la menor base sobre Derecho constitucional, pensando que con una simple lectura de la Constitución se tenía autoridad suficiente para hablar sobre estos temas. Recuerdo que en alguna oportunidad el egregio Carnelutti llamó la atención sobre el hecho de que si bien es cierto que el Derecho procesal civil se condensa en el respectivo Código Procesal, uno es diferente del otro. Tan sabio consejo lo seguían los civilistas, los procesalistas, los penalistas, mas no los que fungían de constitucionalistas. Esto por cierto tenía su explicación, pero ello no impedía dejar anotado el hecho y sobre todo los peligros que encerraba. Además no existía, por lo menos hasta donde alcanzaban mis informaciones, nada parecido que tuviese ese enfoque y sobre todo tales dimensiones. Mientras tanto, mi texto ha alcanzado ya sus años y ha tenido cierta difusión.

Pero lo importante para mí es que este breve artículo ha tenido más éxito del que esperaba. No sólo se ha reproducido abundantemente con el sistema de la fotocopiadora, sino que ha tenido varias ediciones; una de ellas en forma de folleto impreso, auspiciada por jóvenes profesores sanmarquinos (Ediciones Jurídicas, Lima, 1994). Esto es lo que me ha llevado a leerlo nuevamente, diez años más tarde, y a escribir estas líneas a distancia.

\section{II}

La primera observación que cabe hacer, pasados estos diez años, es que la crisis por la que el país atravesaba, continúa. Es cierto que a partir de 1990 se ha hecho un esfuerzo serio para dominar la inflación y para combatir al terrorismo, nuestros dos grandes flagelos. En tal sentido, se ha vuelto a la estabilidad económica y al movimiento empresarial y financiero en forma ordenada. Igualmente, hay tranquilidad interna y se nota mayor orden y paz en las ciudades. Hoy en día la experiencia del 
gobierno aprista (1985-1990) parece una pesadilla muy lejana, y existen buenas señales de que las cosas irán para mejor. Mas esto no es suficiente, pues sigue la recesión, la desocupación y los bajos ingresos. Pero al darse los pasos para superar la crisis, han renacido las esperanzas, lo que decididamente es positivo.

\section{III}

Un hecho saltante de los últimos años es, sin lugar a dudas, la caída del muro de Berlín en 1989, y finalmente el derrumbe de la URSS, en 1991. Nunca nadie pensó que esto sucedería y menos aún que fuese tan rápido. Ni siquiera los más agudos analistas del fenómeno ruso, dispersados entre los Estados Unidos y la Europa occidental, previeron el colapso soviético. Fue, si se quiere, un hecho inesperado. Nadie pensó que la perestroika iniciada por Gorbachov diese resultados, y que éstos fuesen tan rápidos y sobre todo tan fulminantes. Por cierto, queda todavía el experimento bastante curioso de la República Popular China, mezcla de liberalismo económico con dictadura comunista. Pero se trata de algo supérstite (como es el caso de Cuba), que ya no tiene ni futuro ni menos aún el valor paradigmático, casi modélico, que tuvo la URSS durante toda su historia.

Al caer la URSS han caído muchas cosas. En primer lugar, toda la propaganda empalagosa que tenía montada el aparato soviético en el exterior, destinada a captar adeptos y a estigmatizar a los adversarios. El comunismo, fiel heredero de Marx en este punto, se especializó en el arte de la propaganda (cuyo artista genial fue Goebbels), y en la técnica del ataque consistente no en pulverizar la tesis opuesta, sino en denostar al oponente. Los comunistas, tanto los de dentro como los de fuera, vivieron en y para el insulto. Con esto lograron chantajear a mucha gente de buena fe, en nombre de nobles ideales o de reivindicaciones justas. Para el intelectual honesto, fue además un serio problema que había que analizar, más aún cuando en el caso del Derecho constitucional era la URSS, como nadie lo ponía en cuestión, uno de los modelos constitucionales que había que tener en cuenta (si bien nada original, pues descendía de esquemas creados al compás de la Revolución francesa). Pero este modelo constitucional, estudiado por todos los comparatistas, no existe más. Por tanto, salvo razones históricas, no tiene sentido estudiarlo ni considerarlo en los análisis globales. Peor aún si se constata que el fenómeno comunista, en cuanto sistema político, ha tenido muy corta duración: en rigor desde 1918 (fecha de su primera Constitu- 
ción), hasta su caída en 1991; es decir, setenta y tres años; inferior a las grandes dinastías despóticas de Oriente, e incluso de algunos imperios de la antigüedad. Por cierto, el discurrir apresurado de nuestro siglo ha contribuido a erosionarlo más rápido de lo que se pensó, y es probable que en otras épocas hubiera demorado más en desplomarse.

Tan pronto el sistema empezó a desmoronarse, incluyendo aquí a las llamadas democracias populares del Este, se sucedió una literatura de vértigo tratando de explicar lo ocurrido, y sobre todo, lo que quedaba de ello. En este momento recuerdo los ensayos de Ralf Dahrendorf (Reflexiones sobre la revolución en Europa), Maurice Duverger (La tortuga liberal y la liebre europea) y Giovanni Sartori (La democracia después del comunismo). Esto, conjuntamente con las predicciones triunfalistas de Fukuyama, ha llevado a diversas acciones que no se sabe si tendrán asidero en el futuro. Es evidente que del constitucionalismo soviético no quedará nada, pues el mismo Occidente que lo creó lo había dejado atrás hacía tiempo. Pero en lo concerniente a puntos muy concretos, como por ejemplo la importancia dada a los derechos económicos y sociales, la última palabra no está dada todavía. El comunismo, como aplicación práctica de una doctrina, el marxismo, ha demostrado su fracaso. Pero como expresión teórica, como descubridora de muchas verdades, como reflejo de muchas aspiraciones, su futuro es incierto. Aún más: los problemas que el marxismo dejó en herencia, no todos han sido resueltos, y no se sabe si lo serán por las democracias occidentales. En todo caso, un liberalismo nuevo y en cierto sentido distinto del clásico ha tomado asiento en todas nuestras latitudes, con fervor inusitado, sin saberse hasta ahora si dará sus frutos de la manera como se presenta (lobbys, alta tecnología, rol del Estado, comercio a escala mundial, etc.). Por tanto, si bien superado como modelo, algunas de sus verdades siguen sobre el tapete, y esto es lo que el pensamiento tendrá que ir matizando y filtrando en el futuro. Aquí nos limitamos, por falta de espacio y sobre todo por falta de perspectiva, a dejar apuntada esta inquietud.

\section{IV}

Aspecto importante en nuestra realidad, es la que ha surgido del golpe de Estado de 1992 y de la subsiguiente Constitución de 1993, actualmente vigente. Como sucedió en otras épocas, aun cuando con matices de diferencia, el presidente Fujimori dio un golpe de Estado tan sólo para afianzarse en el poder y ejercerlo sin trabas. La posterior Constitución sólo fue un justificativo de su accionar, y si bien tiene aspectos muy 
puntuales montados especialmente para él (como, por ejemplo, el aumento de sus poderes y la reelección inmediata), la nueva Carta, gracias a la crítica e iniciativas de la oposición, recoge gran parte de los postulados de la de 1979, si bien con un espíritu distinto en lo económico, pero que puede servir como instrumento democrático de gobierno si es que se dan otras condiciones. Si bien es mala la práctica de cambiar de Constitución con tanta frecuencia, más aún cuando la de 1993 se parece tanto a la de 1979, no se sabe qué pasará con la nueva Constitución y cuál sea su destino. Unida en su nacimiento al designio de un hombre, es probable que siga su suerte, si bien esto sólo lo decidirá el futuro (para un análisis de los últimos años, cf. César Arias Quincot, La modernización autoritaria).

Pero lo anterior no ha afectado nuestra actividad constitucional. Por lo contrario, ha continuado con inusitado fervor la vida académica en todos sus aspectos (publicaciones, congresos, cátedras, etc.), a lo que se agrega la realización de cuatro congresos nacionales de Derecho constitucional, el primero en 1987 y el último en 1993, así como la reciente creación de la Asociación Peruana de Derecho Constitucional, destinada a unir, a nivel nacional, a todos los cultores de nuestra disciplina, en especial a los que se dedican a la docencia universitaria en forma seria y continuada ${ }^{6}$.

En cuanto al panorama bibliográfico reciente, la mejor y más completa edición documental es, hasta ahora, la de Domingo García Belaunde y Francisco Fernández Segado, La Constitución peruana de 1993, Edic. Grijley, Lima, 1993, con textos y comentarios. Un gran panorama, con análisis puntuales, puede verse en el colectivo editado por la Comisión Andina de Juristas: La Constitución de 1993. Análisis y comentarios, Lima, 1993. Existen, por cierto, cantidad de ensayos sobre temas específicos, que pueden ser de interés para el especialista.

Desde un punto de vista de análisis político global, encontramos sugestivo el libro de Pedro Planas, La República Autocrática (utilizando esta categoría política a partir de Leguía, demuestra cómo ha continuado rondando nuestro entorno institucional). Como panorama histórico, breve pero serio, está La República de Franklin Pease G.Y., publicado como tercer tomo de "Perú, hombre e historia", editado por EDUBANCO.

\footnotetext{
6 Problema interesante es la aparición (a partir de 1980) de nuevas hornadas de estudiosos, que han producido una muy seria y copiosa literatura especializada en temas constitucionales. A ella me refiero en forma genérica en mi ensayo sobre El movimiento constitucional peruano.
} 
Desde el punto de vista de la doctrina general, ha continuado la producción bibliográfica en todos los campos (parte de ella traducida al castellano), más aún cuando ha habido cambios normativos de importancia. En América latina existen muchas novedades, en especial en países con una nueva Constitución, como es el caso del Brasil (1988), de Colombia (1991), del Paraguay (1992), así como algunas reformas importantes (en Chile, Bolivia y en México), donde la más sugestiva es la llevada a cabo en la Argentina en 1994. Todo esto ha sido acompañado por numerosas publicaciones en sus respectivos países.

En la bibliografia general, si bien hay muchas novedades (por ejemplo, los Elementos de derecho constitucional de Néstor P. Sagüés, y a nivel politológico el importante libro de Robert Dahl, La democracia y sus críticos), creo que los aspectos bibliográficos centrales mencionados en 1985 se mantienen. Habría que destacar únicamente que, aparte de las producciones monumentales de Linares Quintana y Bidart Campos en la Argentina, hay que tener presente las del profesor brasileño Pinto Ferreira, casi desconocida entre nosotros y sin traducir, pero de muy alto nivel (su última obra importante es Comentários à Constituiçâo brasileira, 7 vols., 1989-1995).

\section{VI}

Como se recordará, mi ensayo de 1985 traía una lista de lo que consideraba eran las obras más importantes en materia constitucional en este siglo. Lista, por cierto, que podría discutirse, y a la que quizá podrían añadirse o quitarse algunos nombres. Pero esto relacionado con el siglo XX. Mas el constitucionalismo, en rigor, se inicia en el siglo XVIII, si bien es cierto que a fines de él. En sus inicios hubo gente de talento que volcó sus esfuerzos en la construcción del nuevo orden; no tanto en el nivel teórico sino en construcciones políticas y en la acción. Por eso es importante tener presente a quienes, en el siglo XIX, han escrito obras clásicas, pues son las que han puesto las bases de nuestra disciplina. Fue así que empecé a armar una lista de no más de diez obras importantes en el siglo pasado, pero de inmediato me tropecé con un dato incontestable: la presencia de muchos autores que estaban a caballo entre la política o la historia y el Derecho constitucional, como era el caso ejemplar de Tocqueville. A fin de tener una mejor perspectiva sobre esto, lo conversé con profesores extranjeros amigos míos, y tuve un fluido intercambio epistolar con Pablo Lucas Murillo de la Cueva, quien me hizo interesan- 
tes atingencias sobre el particular. Pero, acicateado por la curiosidad, le pedí a Lucas Murillo que pidiese a su padre, Pablo Lucas Verdú, me hiciese llegar, en su momento, una lista no mayor de diez libros que él considerase importantes en el constitucionalismo del siglo XIX. Con la generosidad de maestro que lo caracteriza, Lucas Verdú me hizo llegar esa lista, que aquí reproduzco como complemento de la que yo realicé, y es la siguiente:

\section{1) Antonio Alcalá Galiano}

Veinte lecciones de Derecho Político Constitucional explicadas en el Ateneo de Madrid, Boix, Madrid, 1843 (hay reedición del CEC).

2) Juan Donoso Cortés

Lecciones de Derecho Politico pronunciadas en el Ateneo de Madrid por J. D. C. (1836-1837), en Obras Completas, B.A.C., Madrid, 1946, tomo I (hay reedición del CEC).

3) J. C. Bluntschli

Derecho Público Universal, Góngora y Cía. Editora, Madrid, 1880, 4 tomos.

4) Albert Häenel

Deutsche Staatsrecht, Verlag von Duncher, Leipzig, 1892.

5) Paul Laband

Le droit public de l'Empire allemand, trad. francesa, V. Giard, Briere, Paris, 1900-1904, 4 vols. La primera edición en alemán es de 1876; la tercera, de 1895, es la que se tradujo al francés.

6) Attilio Brunialti

Il diritto costituzionale e la política nelle istituzioni, UTET, Torino, 1896,2 vols.

7) Vittorio Emmanuelle Orlando

Principii di Diritto Costituzionale, 3. ed., Firenze, 1913.

8) Pellegrino Rossi

Cours de Droit Constitutionneh Paris, 1843.

9) James Bryce

La república norteamericana, La España Moderna, Madrid, 1902 c., 2 vols. 
10) A. V. Dicey

Introduction to the law of the Constitution, London, 1908 (hay traducción francesa: París, 1902).

11) Walter Bagehot

The English Constitution (hay traducción francesa y castellana).

De esta lista, en mi personal opinión, reduciría los nombres españoles de dos a uno y quizá prescindiría de Bluntschli. Y lo que se advierte de antemano, y que es aplicable también a la lista que elaboré en relación con el siglo XX, es la ausencia de juristas norteamericanos, que los hay y muy buenos. En el siglo XIX creo que son importantes Joseph Story, Commentaries on the Constitution of the United States (1833), y Thomas Cooley, $A$ Treatise on the Constitutional limitations (1868), que son dos clásicos. Del siglo XX habría que considerar a Edward S. Corwin, de quien tentativamente prefiero, más que sus libros, algunos de sus ensayos (por ejemplo, el dedicado al control constitucional, o sobre la Higher Law...). Hasta donde estoy informado, de esto no hay traducción al castellano, salvo de la abreviatura de Story, hecha por él mismo y traducida y publicada en Buenos Aires a fines del siglo pasado. Y, por cierto, de numerosos libros de Corwin. Quizá los autores norteamericanos mencionados sirvan más para sus esquemas que para los nuestros. Pero aún así hay que considerarlos, pues dentro de esas obras, a veces desiguales, encontramos aportaciones interesantes.

\section{VII}

Estas líneas, como queda dicho, son tan sólo comentarios de actualización en forma de notas sueltas y dentro de los límites que me impuse en mi texto primigenio. Pero, salvando los detalles que nunca faltan, creo que lo expresado en 1985 sobre lo que es el Derecho constitucional, cómo estudiarlo y cómo investigarlo, sigue en pie. Por cierto, hoy lo habría escrito y presentado de manera distinta, pero no hubiera cambiado lo que en sustancia señalé en aquella oportunidad.

Lima, noviembre de 1995. 